\title{
Conflicto por la tierra y movimiento campesino. Un estudio de caso: Colonia Guahory del Distrito de Tembiaporá del Departamento de Caaguazú, Paraguay (2016-2017)
}

\section{Conflict by the land y peasant movement. A case study: Colonia Guahory del Tembiaporá District of the Department of Caaguazú, Paraguay (2016-2017)}

\author{
Omar Tadeo Yampey Díaz
}

\begin{abstract}
Resumen
La investigación demuestra que el conflicto por la tierra es un fenómeno de desplazamiento y -contradictoriamente- recreación del campesinado. Además, el proceso evidencia una combinación tipológica de desalojo forzoso, lucha por la tierra y resistencia al modelo de agroexportación.

En términos sociológicos se caracteriza el proceso de conflicto por la tierra donde el movimiento campesino recupera la Colonia Guahory entre 2016 y 2017 desde la perspectiva de la agencia social.

Dada la naturaleza cualitativa de la indagación, se opta por el estudio de caso que describe en profundidad el conflicto rural. Los datos se recogieron a través de observaciones, entrevistas, análisis de material audiovisual triangulados con información de prensa escrita y análisis académicos y políticos con dirigentes campesinos y especialistas del tema.

Se observa que el proceso de conflicto es un tipo de reocupación de tierras pertenecientes a la comunidad campesina sujeto de la Reforma Agraria. El desencadenante es un desalojo forzoso sin orden judicial llevada a cabo por un fuerte operativo fiscal y policial encabezado y financiado por sojeros brasileros. La movilización campesina transita de una lógica aislada a una territorializada a partir de la inserción de la Federación Nacional Campesina, que despliega un repertorio de acción a escala nacional. La dinámica del conflicto evidencia que los sucesivos desalojos tienen como objetivo el desmantelamiento material y simbólico de la comunidad.

La investigación sobre el conflicto es estratégica para plantear reformas necesarias de las instituciones del Estado con el fin de garantizar los derechos humanos del campesinado.
\end{abstract}

Palabras clave: conflicto rural, movimiento campesino, Guahory. a Universidad Nacional de Asunción, Facultad de Ciencias Sociales, Paraguay.

Correspondencia a: turcomano1@gmail.com

Recibido:

24 octubre 2019

Aceptado:

6 diciembre 2019

Artículo publicado en acceso abierto bajo la Licencia Creative Commons.

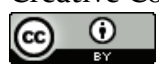

Cita:

Yampey Díaz, O. T. (2019).

Conflicto por la tierra y movimiento campesino. Un estudio de caso: Colonia Guahory del Distrito de Tembiaporá del Departamento de Caaguazú, Paraguay (2016-2017). Kera Yvoty: reflexiones sobre la cuestión social, 4, 17-27. 
Yampey Díaz, O. T. Conflicto por la tierra y movimiento campesino. Un estudio de caso: Colonia Guahory del Distrito de Tembiaporá del Departamento de Caaguazú, Paraguay (2016-2017).

\begin{abstract}
Research shows that the conflict over land is a phenomenon of displacement and - contradictorily - recreation of the peasantry. In addition, the process shows a typological combination of forced eviction, struggle for land and resistance to the agro-export model.

In sociological terms, the process of conflict over land is characterized where the peasant movement recovers Guahory Colony between 2016 and 2017 from the perspective of the social agency.

Given the qualitative nature of the inquiry, the case study that describes in depth the rural conflict is chosen. Data were collected through observations, interviews, analysis of triangulated audiovisual material with written press information and academic and political analysis with peasant leaders and subject specialists.

It is observed that the conflict process is a type of land reoccupation belonging to the peasant community subject to the Agrarian Reform. The trigger is a forced eviction without a warrant carried out by a strong fiscal and police operation headed and financed by Brazilian partners. The peasant mobilization transits from an isolated logic to a territorialized one from the insertion of the National Peasant Federation, which displays a repertoire of action at national level. The dynamics of the conflict show that the successive evictions are aimed at the material and symbolic dismantling of the community.

The investigation into the conflict is strategic to propose necessary reforms of the State institutions in order to guarantee the human rights of the peasantry.
\end{abstract}

Keywords: rural conflict, peasant movement, Guahory.

\section{Introducción}

"Sostener que el campesinado es una clase significa trabajar aquí y ahora para que lo sea". Armando Bartra. Campesindios (2010).

El estudio del conflicto por la tierra cobra, en la actualidad, más relevancia que nunca. El signo de este tiempo es la extranjerización de las tierras y la pérdida de soberanía productiva y alimentaria en el Paraguay.

Las tierras de Guahory son una radiografía de las amenazas que se ciernen sobre los territorios campesinos en el país. En torno a ella se encuentran amenazadas directamente otras comunidades del departamento de Caaguazú.

En términos generales, de 3.500.00o hectáreas destinadas a la Reforma Agraria, el $45 \%$ se encuentra en manos de no sujetos y extranjeros, y sólo un 5 a $10 \%$ cuenta con título de propiedad (Entrevista 3). Por otra parte, la ocupación y recuperación de las tierras en Guahory va a contra marcha de la caracterización que realizan Palau et al. (2018) del tercer momento de la dinámica del movimiento campesino paraguayo de "ritualización de los repertorios de acción clásicos”.

Teniendo en cuenta estos aspectos de estructura y agencia social, la investigación pretende caracterizar el proceso de conflicto por la tierra en la Colonia Guahory teniendo en cuenta las dimensiones desencadenantes y la dinámica de la movilización a partir de las preguntas: cuándo inicia y contra qué es el conflicto.

El estudio se encuadra dentro del área temática de la sociología rural y de los movimientos sociales. Se adopta el modelo de análisis propuesto por Galafassi (2006) quien plantea una crítica al paradigma neofuncionalista del análisis de los movimientos sociales. Y propone una síntesis para analizarlos, integrando las dimensiones estructurales, políticas y culturales que los explican. Priorizando "tal como lo hacen los propios movimientos sociales, la disputa, el conflicto, la lucha entre clases o fracciones de clase y la confrontación entre modelos de sociedad" (p. 55).

Conceptualmente el conflicto se 
entiende como "proceso de interacción contenciosa entre actores sociales que comparten orientaciones cognitivas, movilizados con diversos grados de organización y que actúan colectivamente de acuerdo con expectativas de mejora, de defensa de la situación preexistente o proponiendo un contraproyecto social" (Cadarso, 2001, p. 12).

Esto se traduce en que el caso Guahory no es un evento o dato llamativo sino un proceso histórico, condicionado por estructuras objetivas que posibilitan o impiden la experiencia de los agentes sociales. Además, es una disputa entre el modelo de ser y producir campesino y el de los agronegocios.

El siglo XX ha sido testigo del rol fundamental que tuvo el campesinado en los procesos de rebeliones y revoluciones que impactaron a escala global (Wolf, 1979).

Esto no modificó el pesimismo hacia el campesinado y su "pasividad". Desde distintas disciplinas de las Ciencias Sociales Marx (1971), Wolf (1971, 1979), Hobsbawm (1998a) y Shanin (1979) coinciden en la hipótesis del "escaso carácter de clase" y la élite externa al campesinado que la dirige.

A finales del siglo XX y en lo que va del presente, dicha hipótesis ha sido refutada por la emergencia de una tercera ola histórica de movimientos sociales "que se formaron en el sector rural, tienen una base campesina y son conducidos por campesinos" (Veltmeyer, 2008, p. 324). Este fenómeno se desarrolla en contextos de países periféricos de acumulación capitalista desarticulada, donde persiste un sector rural semiproletarizado que políticamente tiene diferentes modos de movilización y emplean la táctica de la ocupación de tierras (Moyo \& Yero, 2008). Para Veltmeyer y Petras (2002) entre estos movimientos rurales se encuentran el EZLN en México, el MST en Brasil, el CONAIE en Ecuador y la FNC en Paraguay.

Hobsbawm (1998b) a partir de estudios de casos en Perú define a la ocupación de tierra como la acción colectiva fundamental del campesinado tradicional, analiza el tipo de "recuperación o reocupación" de tierras que pertenecían a los campesinos y fueron usurpadas. Para el autor existe un patrón que siguen las ocupaciones de tierra donde se debate colectivamente, se realiza una campaña de propaganda y se elabora una mística y agitación artística representativa.

El geógrafo brasilero Mançano (2008) a partir del estudio de caso del MST del Brasil señala que organizar una ocupación proviene de la necesidad de supervivencia e incorpora las variables de organización y experiencia de lucha a la tipología de Hobsbawm (1998b). La primera variable subdivide en aislados y territorializados; $y$, la segunda en espontáneos/organizados aislados y organizados espacializados.

A partir de estudios de caso en Argentina, Domínguez (2009) identifica que el movimiento campesino combina dos vías de acción en el marco de la lucha por la tierra, directas de resistencia y legales de gestión. Las principales motivaciones de los conflictos son desalojos, acceso a la tierra y contra desmontes.

En Paraguay, la cuestión campesina ha sido abordada desde distintas disciplinas atravesando las etapas pre-sociológicas hasta la sociología científica (Heiseke, 1965). Actualmente coexisten paradigmas y estilos que abordan la problemática. Se identifican a Lara Castro (1985), Fogel (2001, 2005), Galeano (1990, 2016), Palau y Heikel (2016), Riquelme (2001), Rojas (2016, 2017) Palau (2018). Esta corriente utiliza las categorías de clase, estructura de oportunidades políticas, estructura de movilización de recursos, identidad, etc. En mayor o menor medida tiene un compromiso y/o vinculación con el campesinado.

De los 70 conflictos que analiza Riquelme (2001) en $85 \%$ se produjo ocupación.

Delgado (2008) describe el mecanismo que utiliza la FNC para la ocupación: primero se forma una comisión vecinal, se analizan y definen criterios de las tierras a ser ocupadas, se priorizan 
Yampey Díaz, O. T. Conflicto por la tierra y movimiento campesino. Un estudio de caso: Colonia Guahory del Distrito de Tembiaporá del Departamento de Caaguazú, Paraguay (2016-2017).

latifundios improductivos y/o malhabidos. Según el Libro Blanco de la FNC (2017) el acceso a la tierra de los campesinos se da mediante dos mecanismos: a través de sus propios ingresos y como resultado de las ocupaciones en la lucha por la tierra. La FNC hasta el 2003 llegó a conquistar 300 mil hectáreas con la conformación de 41 asentamientos.

El Caso Guahory evidencia patrones similares a otros conflictos por la tierra en términos de respuesta de las instituciones del Estado (Vuyk, 2017; González, 2016).

Finalmente, tomando como referencia el inventario de conflictos elaborados a partir de Fogel (2001), Riquelme (2001) y Palau \& Areco (2016), se deduce que la ocupación de Guahory combina resistencia al desalojo forzoso, lucha por la tierra y resistencia al cultivo de soja.

\section{Objetivos \\ General}

Caracterizar el proceso de conflicto por la tierra en la Colonia Guahory entre 2016 y 2017; para conocer los desencadenantes, las etapas de la movilización y los resultados

\section{Específicos}

Identificar factores desencadenantes del conflicto por la tierra en la Colonia Guahory

Examinar la dinámica del conflicto para comprender las etapas de la movilización y resultados.

\section{Materiales y Métodos}

La estrategia metodológica utiliza el estudio de caso en un nivel descriptivo desde la perspectiva de investigación cualitativa.

El estudio de caso examina el fenómeno contemporáneo en su entorno real, utiliza múltiples fuentes de datos, busca dar respuesta a cómoy porquéocurren los fenómenos (Martínez, 2006). En ese sentido el caso es instrumental permitiendo iluminar el contexto problemático más amplio sobre la situación de comunidades aledañas y del proceso histórico de la colonización oficial en Paraguay.

El nivel descriptivo del estudio refiere a que "trabaja sobre realidades de hecho y su característica fundamental es registrar con rigor las características y propiedades de los hechos observados" (Ramírez \& Morales, 2015, p. 17).

La investigación cualitativa parte de supuestos donde "la realidad es subjetiva y múltiple; el investigador está inmerso en el contexto de interacción que desea investigar; asume sus valores como parte del proceso de conocimiento; y plantea un diseño flexible e interactivo que privilegia el análisis en profundidad y en detalle en relación al contexto" (Sautu et al, 2005, p. 40).

El caso objeto de estudio es el conflicto por las tierras en la Colonia Guahory. Las categorías de análisis utilizadas son conflicto por la tierra, movilización campesina y ocupación de tierras.

En la etapa exploratoria de la investigación se realizaron entrevistas y diálogos con referentes académicos del tema, con militantes y dirigentes de la FNC. Durante esta etapa el conflicto estaba en desarrollo, lo que dificultó organizar visitas esquematizadas para el acceso al territorio. Las mismas se realizaron con la FNC, el MNP, con organizaciones y movimientos sociales y una visita en el marco de una investigación más amplia de especialistas del Lemonde Diplomatiq francés. Realizadas entre enero de 2017 y febrero de 2018.

Las visitas guiadas facilitaron la comunicación con los pobladores de la comunidad.

Se realizaron entrevistas a 14 miembros de la organización y observación participante en las visitas a la comunidad. También se analizaron materiales audiovisuales, 23 videos sobre el desalojo del 15/09/2016 y enfrentamientos del 03/12/2017; 100 imágenes de la visita del 24/o1/2017; y, 72 videos de la visita del 24/02/2018. Para el análisis de documentos escritos y reconstrucción de las etapas del 
conflicto se cuenta con la sistematización de una solicitud de medidas cautelares a la CIDH solicitada por la PEICC. Una denuncia penal presentada por legisladores de la nación. Dos informes oficiales elaboradas por el SIRT/INDERT. Dos informes del MNP y un informe de la SNNA.

Además, 54 noticias de la web del gobierno (Paraguay IP); 80 del Diario UH; 36 de medios de la FNC; 18 de la web de la ARP. Los datos fueron codificados manualmente y en el programa ATLAS.TI V6, de acuerdo a las categorías de análisis.

Los primeros avances de la investigación fueron presentados en el I Congreso paraguayo de Ciencias Sociales CLACSO (2017), posterior a la defensa de tesis de grado (2018), se presentó en las XXVII jornadas de jóvenes investigadores AUGM en Brasil (2019).

\section{Resultados y Discusión Colonia Guahory}

Guahory es una de las mil Colonias agrícolas habilitadas por el Estado paraguayo desde 1891 a 2010 (Rojas \& Areco, 2017). El INDERT adquirió 1359 hectáreas entre 1986 y 1997 para fines de la Reforma Agraria (SIRT, 2017). Geográficamente se ubica en el distrito de Tembiaporá del departamento de Caaguazú a 250 kilómetros de la ciudad de Asunción y limita con Alto Paraná separada por el Lago Yguazú. Es lindante con las comunidades de Pindo'i, Pindó Azul, Banderita, Mil palos y Toro Kangué. La ubicación espacial es relevante para comprender que la resistencia en Guahory es la defensa de las demás comunidades. En palabras de un poblador "sigue la resistencia, la lucha, porque sigue la amenaza de desalojo... no hay tranquilidad, se pierde Guahory y se pierden otras comunidades" (Entrevista 4).

A partir de datos del 2015 proveído por el INDERT, se infiere que Guahory es en un 96,2 colonia agrícola, y el 3,8\% quinta. Además, que el territorio está organizado por "líneas". Lo que implica distancias importantes entre las viviendas de los pobladores. Este esquema se diferencia de la organización "nuclear" que permite a la comunidad estar más integrada y compartir espacios comunes.

En cuanto a la tenencia de tierras, sobre un total de 133 lotes identificados un $51 \%$ cuenta con título de propiedad y el $49 \%$ no. Del total de los que cuentan con títulos sólo el $6,8 \%$ consiguió a través del INDERT. Del $77 \%$ de los propietarios no se tienen datos porque no accedieron a responder esa pregunta o porque no viven en el lugar. En cuanto a vivienda, el $22 \%$ posee, un $69,2 \%$ no posee y el $8 \%$ está deshabitada.

La dimensión productiva es desalentadora, el $\mathbf{2 2} \%$ afirmaba tener cultivos agrícolas. Esto no es casualidad, ya que sólo el $8 \%$ accede a créditos productivos que provienen en su mayoría del sector privado; y, ningún poblador cuenta con algún tipo de asistencia técnica.

En términos organizativos el 2,3\% afirmó ser participante de alguna organización.

A todo esto, se agrega la situación de los niños, niñas y adolescentes de la comunidad, que según el informe de la SNNA (2017) muchos de ellos se encuentran sin acceso a la identidad, a la salud, a la alimentación y al agua potable. Además, fueron víctimas de agresiones físicas y psicológicas en los desalojos.

\section{Detonantes del conflicto}

Como ha sido señalado más arriba la ausencia del Estado es absoluta en términos de cumplir el Estatuto Agrario para consolidar el arraigo de la comunidad, pero relativa en términos del uso de la fuerza para la defensa de los intereses extranjeros. El día 15/o9 de 2016 en horas de la mañana se realizó un desalojo forzoso entendido como "el hecho de hacer salir a personas, familias y/o comunidades de los hogares y/o las tierras que ocupan, en forma permanente o provisional, sin ofrecerles medios apropiados de protección legal o de otra índole ni permitirles su acceso a ellos" (CDESC-ONU en Ayala, 2016). Sin contar con orden judicial, 1200 efectivos policiales de grupos especiales (GEO y 
Yampey Díaz, O. T. Conflicto por la tierra y movimiento campesino. Un estudio de caso: Colonia Guahory del Distrito de Tembiaporá del Departamento de Caaguazú, Paraguay (2016-2017).

FOPE) fuertemente armados ingresaron a la comunidad y procedieron a expulsar a los pobladores. Tractores y topadoras conducidas por empresarios agroganaderos brasileros destruyeron viviendas (Ñanduti, 2016), cultivos, envenenaron pozos de agua y se llevaron pertenencias y animales de las familias campesinas.

Un productor brasilero agradeció al gobierno del entonces presidente Horacio Cartes (2013-2018) porque "dio luz verde para que se haga limpieza y que la ley paraguaya sea hecha, así como nos autorizó" (Ñanduti, 206). Dos datos no menores son que el operativo se orientó desde un helicóptero prestado por la Entidad Binacional Yacyretá; además, los empresarios brasileros admitieron pagar USD 200.000 a la policía para llevar a cabo el desalojo (UH,18/19/16).

En su momento Justo Cárdenas, presidente del INDERT, reconoció que un funcionario del ente fraguó documentos de estas propiedades. A su vez, la representante legal de los campesinos, relató el modus operandi. "Éste utilizaba como prestanombres a sus hermanos y a su madre, para hacerse de títulos de propiedad y luego negociarlos con los brasileños" (UH, 15/09/16).

El desalojo forzoso visibiliza la situación de la tenencia de tierras, la inconstitucionalidad de entrega de títulos a no sujetos de la reforma agraria y la ilegalidad del procedimiento de desalojo.

\section{Dinámica del Conflicto}

El "ellos" y el "nosotros"

A partir de una entrevista colectiva a pobladores sobre la diferencia entre la agricultura campesina y la de agroexportación, se identificó un "nosotros" como identidad del ser, producir y vivir campesino. Y un "ellos” refiriéndose a los sojeros brasileros.

Ellos: acceden a títulos fraguados, no viven acá, plantan acá y llevan todo, se benefician de nuestras tierras. Tienen ayuda del gobierno. Producen soja que beneficia sólo a los empresarios. Dañan la salud y al medioambiente

Nosotros: producimos alimentos sanos, de la tierra a la mesa para cocinar. Nuestra producción alimenta también a la ciudadanía. Notenemos ayuda del gobierno. Con la producción hacemos estudiar a los niños, salud, vestimenta. Cuando podemos vender nuestra producción los niños se alegran, tienen zapatos, comen helado, van a la cancha (Entrevista 6).

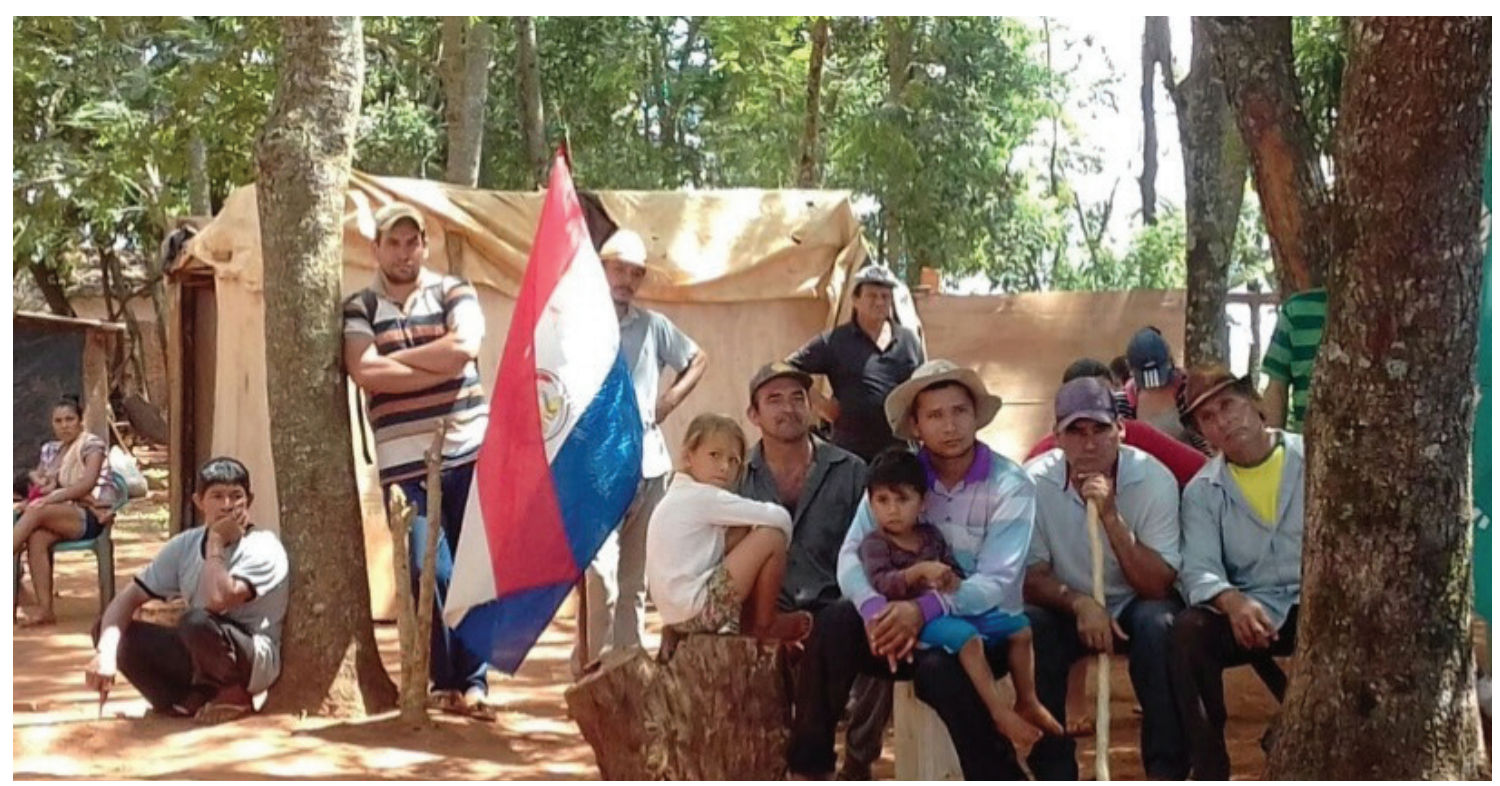

Figura 1. Asamblea de Campesinos.

Fuente. Autor. 


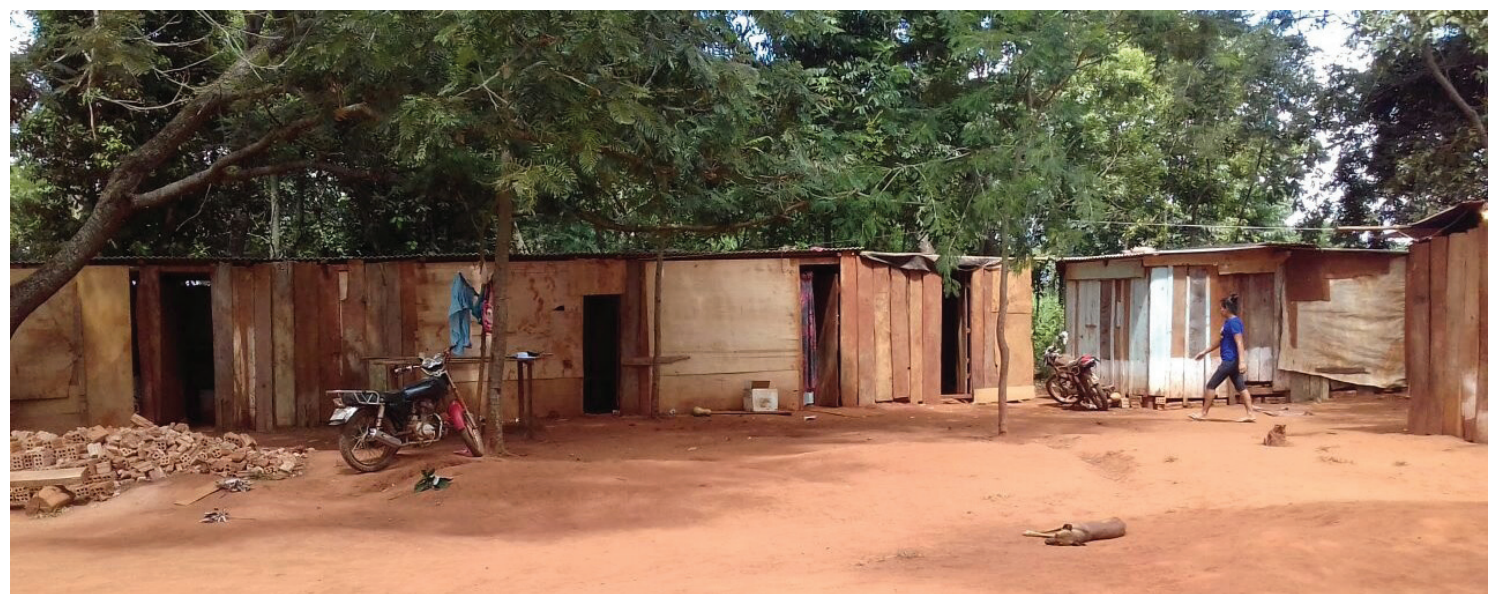

Figura 2. Campamento Centralizado.

Fuente. Autor.

El grado de conciencia sobre la identidad, la pertenencia y la diferencia con el "ellos" motorizan el proceso que se describe a continuación.

\section{Etapa: Movilización y reocupación}

El primer momentodela movilización se da a raíz del desalojo forzoso del 15/o9/16 donde se presenta el Proyecto de Ley $\mathrm{N}^{\circ}$ 5.808 "Que declara de interés social y expropia a favor del INDERT", para los fines de reforma agraria e inicia una serie de movilizaciones con el objetivo de recuperar las tierras. Entre el 26/o9 y 19/10 de 2016 los campesinos se movilizan en Asunción dirigidos por la comisión vecinal "Paraguay primero" en alianza con sectores de partidos tradicionales. Se plantea la consigna "Guahory es Paraguay" y se coloca la problemática en la agenda política y mediática sin mayores resultados.

El segundo momento, es a partir de la asamblea popular realizada el 26/10 de 2016. En esta se inserta la FNC y plantea la consigna de la "Lucha por la tierra: organización, autodeterminación y resistencia" del campesinado y se define reocupar el territorio.

Para Riquelme (2001) la estrategia de ocupación de tierra lleva un largo proceso de preparación. "No se trata de una acción que responde a un mero espíritu aventurero, sino de una acción donde el liderazgo debe concentrar toda su capacidad y su habilidad para manejar un grupo numeroso de personas para enfrentar con éxito la presión que ejercen los propietarios y sus organizaciones, los jueces y sobre todo las fuerzas policiales y los grupos de civiles armados, o paramilitares. Si no cumplen este proceso mínimo, las ocupaciones están destinadas al fracaso" (p. 151).

En Guahory la organización giró en torno a centralizar los campamentos para recuperar las tierras. Un dirigente de la FNC define de la siguiente manera "la organización significa hacer olla popular, significa hacer para tu baño, significa hacer tu carpa, organización significa tener víveres para la resistencia, tema logístico, seguridad, preparación para la lucha" (Entrevista 1).

Se sugiere que en este proceso el campesinado pasa de una experiencia espontánea y aislada a una organización territorializada y espacializada desde la inserción de la FNC y su capacidad de movilización nacional. En ese sentido, se realizaron denuncias en instituciones públicas, mitines, marchas y cierres de ruta en diferentes puntos del país apoyando la causa de Guahory.

A esto se agrega el contraste con el escaso $2,3 \%$ que formaba parte de alguna organización en 2015 a una alta participación en las asambleas e identificación con la FNC. 
Yampey Díaz, O. T. Conflicto por la tierra y movimiento campesino. Un estudio de caso: Colonia Guahory del Distrito de Tembiaporá del Departamento de Caaguazú, Paraguay (2016-2017).

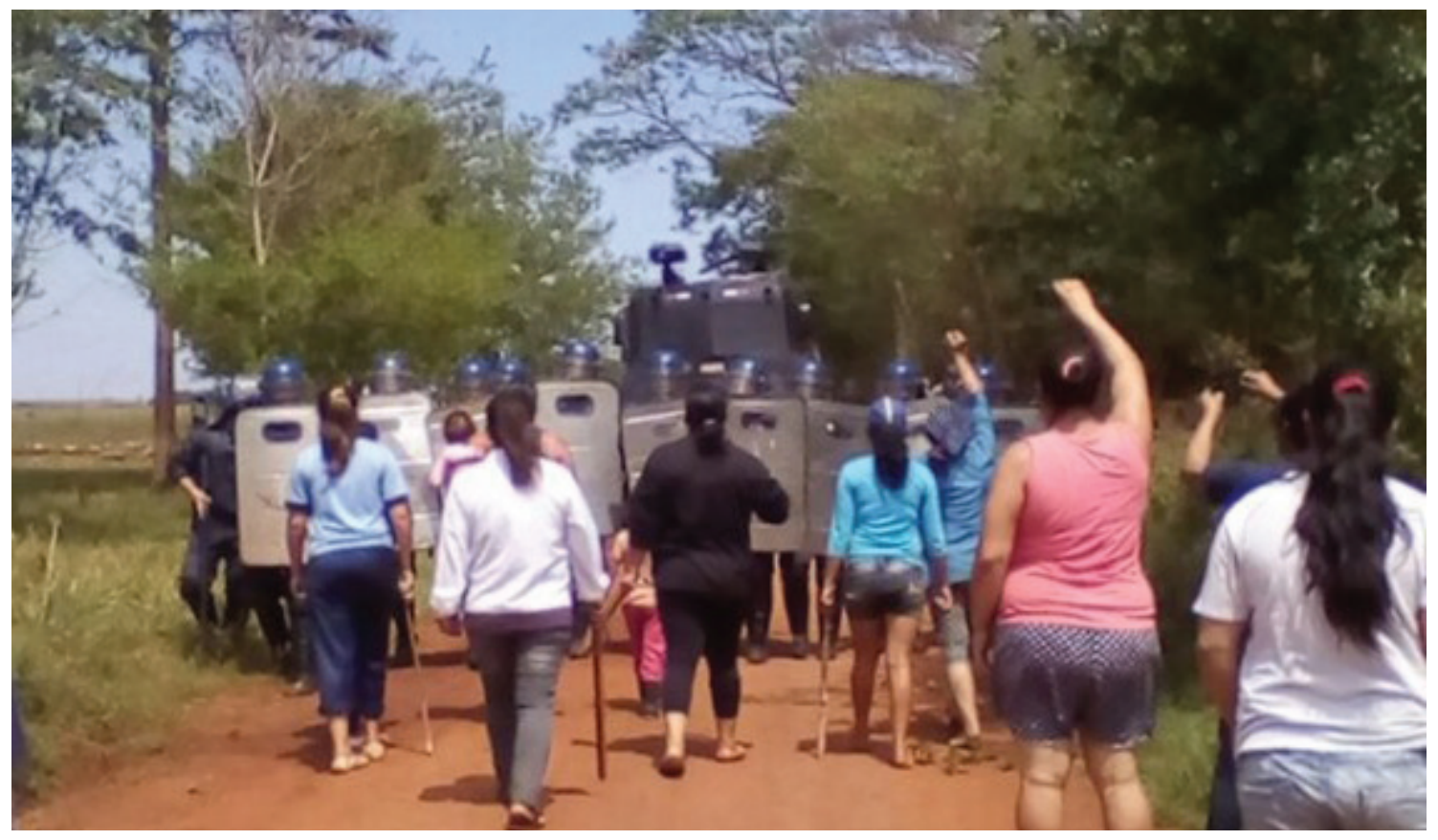

Figura 3. Resistencia de las mujeres.

Fuente: UH, 08/10/2016.

El caso más emblemático es el de una joven lideresa de la comunidad que se incorporó a la dirección nacional de la FNC en el año 2017. En sus palabras "como resultado de los debates después del desalojo del 2016 definimos que las mujeres también debemos confrontar. Así fue que las mujeres varias veces hicimos retroceder a los carros hidrantes; después de eso, ellos ya no nos atropellaron porque se hicieron muchas denuncias y publicaciones a nivel nacional e internacional. Ahora acompañan nuestra causa los intelectuales, la ciudadanía que se indignan como nos maltratan" (Entrevista 2).

Este relato coincide con las expresiones de un dirigente de larga trayectoria "entre el primer y segundo desalojo, ahora hay otro proceso, donde se debate. Entonces los compañeros y compañeras que quieren para sus tierras y quieren su futuro en sus tierras, entonces luchan por la tierra de forma organizada" (Entrevista 1).
Etapa: Tregua, negociación y conquista

El INDERT plantea un diálogo entre las partes y propone una solución mixta al conflicto. Guahory se divide entre la posición de la comisión vecinal que acepta la reubicación en Yhú a mediados de diciembre de 2016. Y la mayoría que acompaña el planteamiento de la FNC de reocupary conquistar las tierras. El o2/o2/17 se conquistan 250 hectáreas y se adjudican a 27 pobladoras y pobladores los lotes.

\section{Etapa: Regreso a las confrontaciones}

Se dan el tercer, cuarto y quinto sucesos del desalojo forzoso en las fechas 27/12/2016, 03/01/2017 y 08/05/17. A raíz de resistencias al cultivo de soja y a la fumigación. Y configuran la secuencia completa del desmantelamiento material y simbólico de la comunidad, donde son destruidas más viviendas, puentes y caminos, la capilla de la comunidad, se envenenan pozos de agua, se arrasaron cultivos de autoconsumo y se atropella una de las escuelas de la comunidad. Además, 
los intervinientes robaron las pertenencias de los pobladores (dinero y celulares) y se llevan las motocicletas de los mismos (Entrevista 5). Se realizan detenciones e imputaciones arbitrarias, y queda un saldo importante de personas heridas ${ }^{1}$.

\section{Etapa de veto y "autodefensa}

Finalmente, el 23/05/2017 el entonces presidente Horacio Cartes veta la ley de expropiación en favor del INDERT. Esto desata un nuevo momento de movilizaciones repudiando la decisión del ejecutivo y de incertidumbre en Guahory. Ante el amedrentamiento de civiles armados y las reiteradas denuncias ante las instituciones del Estado, la FNC en reunión con el ministro del Interior y el jefe de Orden y Seguridad de la Policía Nacional advierte que "si no se soluciona el problema, nosotros como organización prepararemos nuestra propia defensa contra civiles armados" según declaró a medios de prensa la secretaria general Teodolina Villalba (UH, 14/06/17).

\section{Conclusiones}

La organización territorial de Guahory, la inseguridad en la tenencia de tierra, la escasa asistencia técnica y crediticia para producir, el bajo nivel de integración y arraigo en la comunidad contraviene lo establecido por el Estatuto Agrario del INDERT y son prerrequisito para el proceso de conflicto. El objetivo del desalojo forzoso del 15/o9/16 es inconcluso debido a la resistencia campesina. Los sucesivos ataques a la comunidad evidencian la continuidad y sistematicidad de las fuerzas públicas para desmantelar material y simbólicamente Guahory. La acción del campesinado organizado en la FNC es simultáneamente defensivo y ofensivo. Se conquistan tierras, se incorporan miembros a la organización, se utilizan métodos democráticos de toma de decisiones, se rearticula la producción

1 En total se contabilizan 32 imputaciones, 35 detenciones y 50 personas heridas. y los lazos sociales de la comunidad, se da seguridad y se protegen los bienes de la población en una perspectiva más amplia de reforma agraria de base en oposición al modelo de agroexportación.

En una palabra, lo que el Estado paraguayo no hace, lo hace la organización popular.

\section{Referencias Bibliográficas}

Ayala, O. (2016). La privación arbitraria de la vivienda y tierra como cuestión vertebral de la política de criminalización de las demandas económicas y sociales. En Codehupy (Ed.), Yvypóra Derécho Paraguáipe. Derechos Humanos en Paraguay 2016. Asunción: Codehupy.

Bartra, A. (2010). Campesindios. Aproximaciones a los Campesinos de un Continente Colonizado. Ciudad: sn.

Cadarso, P. (2001). Fundamentos teóricos del conflicto social. Madrid: Siglo XXI.

Delgado, V. (2008). Ñandekuéra: todos nosotros. Asunción: ediciones Néike.

Domínguez, D. (2009). La lucha por la tierra en Argentina en los albores del Siglo XXI. La recreación del campesinado $y$ de los pueblos originarios. Buenos Aires: UBA.

Federación Nacional Campesina, FNC. (2017). Libro Blanco.

Fogel, R. (2001). La estructura y la coyuntura en las luchas del movimiento campesino paraguayo". en, una nueva ruralidad en América Latina. Buenos Aires: CLACSO.

Fogel, R. (2005). La Estructura y la Coyuntura en las luchas del Movimiento Campesino paraguayo. En: Una nueva ruralidad en América Latina. Buenos Aires: CLACSO.

Galafassi, G. (2006). Cuando el árbol no deja ver el bosque. Neofuncionalismo y posmodernidad en los estudios sobre movimientos sociales. Revista Theomai, 37-58.

Galeano, L. (2016). Transformación del modelo agrícola y cambios en la 
Yampey Díaz, O. T. Conflicto por la tierra y movimiento campesino. Un estudio de caso: Colonia Guahory del Distrito de Tembiaporá del Departamento de Caaguazú, Paraguay (2016-2017).

estructura de clases. En L. Ortiz (Ed.), Desigualdad y clases sociales. Estudios sobre la estructura social paraguaya. Asunción: CEADUC/CLACSO/ICSO.

González, J. (2016). Informe Especial. "Paraguay: el "Nuevo Rumbo" apura el acaparamiento de tierras campesinas $e$ indígenas al cumplir sus tres años". Asunción: Base IS.

Heisecke, G. (1965). La bibliografía sociológica en el Paraguay. Revista Paraguaya de Sociología, 55-70.

Hobsbawm. E. (1998a). Os Camponeses e a Política. En Pessoas Extraordinárias, resistência, rebelião e jazz. São Paulo: Editora Paz e Terra.

Hobsbawm. E. (1998b). Ocupações de Terra por Camponeses. En Pessoas Extraordinárias, resistência, rebelião $e$ jazz. São Paulo: Editora Paz e Terra.

Lara Castro, J. (1985). Las luchas sociales y nacimiento del Movimiento Campesino. En América Latina: Historia de medio siglo. México D.F: Siglo XXI.

Mançano, B. (2008). La ocupación como una forma de acceso a la tierra en Brasil: una contribución teórica $y$ metodológica. En S. Moyo y P. Yeros (Ed.), Recuperando la tierra. El resurgimiento de movimientos rurales en Africa, Asia y América Latina. Buenos Aires: CLACSO.

Martínez, P. (2006). El método de estudio de caso: estrategia metodológica de la investigación científica. Pensamiento $\mathcal{E}$ Gestión, (20), p. 165-193.

Marx, C. (1971). El campesinado como clase. En publicación: Campesinos y Sociedades Campesinas. En: T. Shanin (Ed.), México D.F: Fondo de Cultura Económica.

Moyo, S., \& Yeros, P. (2008). El resurgimiento de los movimientos rurales bajo el neoliberalismo. En S. Moyo y $\mathrm{P}$. Yeros (Ed.), Recuperando la tierra. El resurgimiento de movimientos rurales en Africa, Asia y América Latina. Buenos Aires: CLACSO.
Nanduti. (1 de setiembre de 2016). Impactante video del desalojo en Guahory: "Cartes nos dio luz verde". http://www.nanduti.com. py/2016/o9/19/impactante-video-deldesalojo-guahory-cartes-nos-dio-luzverde/

Ñanduti. (16 de setiembre de 2016). Videos del brutal desalojo de campesinos paraguayos en Tembiaporã. http:// www.nanduti.com.py/2016/o9/16/ videos-del-brutal-desalojocampesinos-paraguayos-tembiapora/

Palau, M. (2018). Canalización de demandas de los Movimientos Sociales al Estado Paraguayo. Asunción: CONACYTPROCIENCIA.

Palau, T., \& Heikel, V. (2016). Los Campesinos, el estado y las empresas: en la frontera agrícola. Asunción: Base IS.

Ramírez, M., \& Morales, M. (2015). Manual para la elaboración de trabajos de investigación de licenciaturas en Ciencias Sociales y Humanidades. Cuernavaca: CRIM, Centro Regional de Investigaciones Multidisciplinarias. UNAM, Universidad Nacional Autónoma de México.

Riquelme, Q. (2001). Los sin tierra en Paraguay: conflictos agrarios $y$ movimiento campesino. Buenos Aires: CLACSO.

Rojas, L., \& Areco, A. (2017). Las Colonias Campesinas en el Paraguay. Asunción: Base IS.

Sautu, R., Boniolo, P., Dalle, P., \& Elbert, R. (2005). Manual de metodología: Construcción del marco teórico, formulación de los objetivos y elección de la metodología. Buenos Aires: CLACSO.

Shanin, T. (1979). El campesinado como factor político. En T. Shanin (Ed.), Campesinos y sociedades campesinas. México: Fondo de Cultura Económica.

Sistema de Información y Registro de la Tierra, SIRT. (2017). Informe Relación de hechos caso: Colonias Guahory y San Sebastián. 
Secretaría Nacional de la Niñez y la Adolescencia, SNNA. (2017). Informe Acciones realizadas Caso GuahoryCaaguazú.

Última Hora. (2016). Desalojo en Guahory habría sido «financiado» por brasiguayos.

Última Hora. (2016). Inminente operativo de desalojo en Guahory.

Última Hora. (2017). Guahory: Campesinos advierten sobre «autodefensa» contra armados.

Veltmeyer, H. (2008). La dinámica de las ocupaciones de tierras en América Latina. En S. Moyo y P. Yeros (Ed.), Recuperando la tierra. El resurgimiento de movimientos rurales en África, Asia y América Latina. Buenos Aires: CLACSO.

\section{Sobre el Autor}

Omar Tadeo Yampey Díaz

Sociólogo, candidato a Máster en Sociología y Ciencia Política de la Universidad Nacional de Asunción. Investigador del Centro de Estudios Heñoi. Militante y dirigente estudiantil por la liberación de la Sociología y la Ciencia Política públicas y la conformación de la Facultad de Ciencias Sociales UNA (2012-2018).
Veltmeyer, H., \& Petras, J. (2002). Los campesinos y el estado en América Latina: Un pasado turbulento, un futuro incierto. Problemas del Desarrollo, 34(131), 7-64. http://www. revistas.unam.mx/index.php/pde/ article/view/7449/6944

Vuyk, C. (2017). Guahory, Curuguaty y Nacunday: los intereses terratenientes y la lucha soberana por la tierra (I). http://www.cyp.org.py/index.php/

Wolf, E. (1971). Los Campesinos. Barcelona: Editorial Labor.

Wolf, E. (1979). Las Rebeliones Campesinas. En T. Shanin (Ed.), Campesinos y sociedades campesinas. México: Fondo de Cultura Económica. analisis/153-guahory-i 